\title{
Two new land planarian species (Platyhelminthes: Tricladida) from the Brazilian Atlantic Forest
}

\author{
Ana Laura Almeida', Raquel Gualda Kishimoto' $\&$ Fernando Carbayo ${ }^{1,2}$
}

\author{
${ }^{1}$ Laboratório de Ecologia e Evolução, Escola de Artes, Ciências e Humanidades, Universidade de São Paulo. Avenida Arlindo \\ Bettio 1000, 03828-000 São Paulo, SP, Brazil. \\ ${ }^{2}$ Corresponding author. E-mail: baz@usp.br
}

\begin{abstract}
The Brazilian Atlantic Forest harbors the world's richest areas of land planarians (Platyhelminthes: Tricladida). Nevertheless, the number of undiscovered species from this biological unit remains seemingly high. Herein we describe Geoplana piriana Almeida \& Carbayo, sp. nov. from the state of Rio de Janeiro, and Geoplana tingauna Kishimoto \& Carbayo, sp. nov. from the state of Santa Catarina. Each species shows a dorsum with a unique color pattern among Geoplaninae species. Their internal morphology also differs: G. piriana sp. nov. shows a unique combination of features, including an extrabulbar, non-bifurcated prostatic vesicle, a non-folded male atrium, a horizontal, cylindrical penis papilla, a female atrium anteriorly narrowed, and lined with an epithelium with multilayered aspect. Geoplana tingauna sp. nov. possesses a prostatic vesicle constituted of a pair of branches opening into the very distal portion of a tubular, unpaired portion, a feature not seen in other Geoplaninae species.
\end{abstract}

KEY WORDS. Flatworms; Geoplaninae; histology; taxonomy.

Land planarians, Geoplanidae Stimpson, 1857, are soil predators reaching high levels of richness in tropical and subtropical forests (see Sluys 1999, Winsor et al. 1998, Carbayo et al. 2002, FICK et al. 2006). Most Neotropical land planarians belong to Geoplaninae, a group comprising ca. 260 species (Ogren et al. 1997). Geoplana Stimpson, 1857 is the richest genus, with over 100 species (TyLer et al. 2006-2011), and occurs from Panamá to Argentina. The genus is diagnosed as Geoplaninae of elongate body form; creeping sole broader than a third of body width; strong cutaneous longitudinal muscles; mc:h value, $4 \%-18 \%$; parenchymal longitudinal musculature, weak or absent, not in a ring zone; testes dorsal; penis papilla present; female canal enters genital antrum dorsally; cephalic glandulo-muscular organs, sensory papillae and adenodactyls absent (Ogren \& KaWAKaTsu 1990). The genus is likely polyphyletic, as inferred from the wide morphological variation, chiefly regarding the copulatory apparatus, as well as from comparative DNA studies (F. Carbayo et al. pers. obs.).

The Brazilian Atlantic Rain Forest harbors the greatest richness of land planarians, especially within areas of the Southeastern and South regions (SLUYS 1999), although this fauna is far from being well known (СаRbayo \& E.M. Froehlich 2008). As a contribution to expand the knowledge of the richness of Geoplaninae, here we describe two new species of Geoplana from the dense ombrophilous forest.

\section{MATERIAL AND METHODS}

The specimens studied were collected manually, mainly during the night, in the Brazilian Atlantic Rain Forest during 2008-2009. They were photographed, and then killed with boiling water. A small piece of tissue was immediately cut off, measured and preserved in absolute ethanol. The worms were fixed with $10 \%$ formalin and subsequently stored in $80 \%$ ethanol. The body was cut into a variable number of pieces, from anterior extremity up to the posterior: anterior region 1 (= anterior tip), anterior region 2, pre-pharynx, pharynx and copulatory apparatus. The pieces were embedded in Paraplast, sectioned at $7 \mu \mathrm{m}$, and stained with Mallory/Cason trichrome stain (RomeIs 1989). Drawings were prepared using a camera lucida. In figures from the lateral aspect, the anterior end of the body is placed to the right. The type-material was deposited in the Museu de Zoologia da Universidade de São Paulo (MZUSP).

List of abbreviations used in the text: (ci) cilia, $(\mathrm{cm}) \mathrm{com}-$ mon muscular coat, (co) common glandular ovovitelline duct, (cr) creeping sole, (de) dorsal epidermis, (e) eye, (es) esophagus, (ej) ejaculatory duct, (fa) female genital atrium, (g) gonopore, (i) intestine, (ls) longitudinal cutaneous muscles, (ly) epithelium of female atrium with multilayered aspect, (m) muscle, (ma) male genital atrium, (mo) mouth, (ov) ovovitelline 
duct, (ph) pharyngeal pocket, (pp) penis papilla, (pv) prostatic vesicle, (px) pharynx, (sd) sperm duct, (sg) shell glands, (sp) supraintestinal traverse muscles, (t) testis, (v) vagina, (vi) vitellaria, (vn) ventral nerve plate.

\section{TAXONOMY}

\section{Systematic account}

Order Tricladida Lang, 1884

Suborder Continenticola Carranza et al., 1998

Geoplanidae Stimpson, 1857

Geoplaninae Stimpson, 1857

Geoplana Stimpson, 1857

\section{Geoplana piriana \\ Almeida \& Carbayo, sp. nov.}

Figs 1-6

Type-material. Holotype: MZUSP PL 1149 (field identification: F2623): Parque Nacional da Serra dos Órgãos, Teresópolis/RJ, Brazil, 22²7'19"S, 4259'51”W, ca. $970 \mathrm{~m}$ above sea level. F. Carbayo et al. leg., 15/VII/2008. Anterior region 1 (= anterior tip): traverse sections on 11 slides; anterior region 2: horizontal sections on four slides; pre-pharyngeal region: traverse sections on three slides; pharynx and copulatory apparatus: sagittal sections on 14 slides; a $2 \mathrm{~mm}$ long piece of tissue anterior to the pre-pharyngeal region was kept frozen in absolute ethanol.

Type locality. Parque Nacional da Serra dos Órgãos, Teresópolis, RJ, Brazil, covered with primary ombrophilous forest.

Diagnosis. Geoplana species, $2 \mathrm{~cm}$ in length. Dorsum with two lateral red brownish to dark brownish bands, formed by small striae, separated from a median black band by thin whitish stripes. Prostatic vesicle extrabulbar, unpaired; male atrium not folded; penis papilla cylindrical, horizontal; female atrium narrow anteriorly, rounded posteriorly; lining of female atrium with multilayered aspect.

Description. At rest, body $20 \mathrm{~mm}$ long and $3 \mathrm{~mm}$ wide. Body lanceolate in dorsal view; maximum width in the pharyngeal region. Dorsum convex, ventral side almost flat. Anterior end rounded, posterior pointed (Fig. 1). Dorsum with whitish background; body margins black in the anteriormost two millimeters. Three bands run along the dorsum: a median homogeneous black band, with a third of body width, running from the apex to nearly posterior end, and two lateral bands. Lateral bands posterior to the two anterior millimeters; composed of small striae shading from red-brown color, in the anterior region, to dark-brown in the posterior. Small striae traverse in the first $1.5 \mathrm{~mm}$, even occupying the whole body width, so that they break the continuity of the median black band. Towards body end, striae smaller, longitudinally arranged, and more densely packed. Posterior end of the body with the background whitish color. Ventral side grayish at the margins of the anterior region, whitish in the rest of the body. After fixation, body $18 \mathrm{~mm}$ long and $3.5 \mathrm{~mm}$ wide (Fig. 1, inset). Mouth at $12 \mathrm{~mm}$ from behind anterior end, gonopore at 14.5 $\mathrm{mm}$. Dorsum color less brilliant and slightly faded than in the live worm. Eyes formed by one pigmented cup, $27 \mu \mathrm{m}$ in diameter, without clear halos around them, and marginally arranged from the very anterior end, contouring it, to the posterior end. Sensory pits as simple invaginations $15 \mu \mathrm{m}$ deep, located ventro-marginally, from the very anterior end up to 5 $\mathrm{mm}$ posterior. Creeping sole with $93 \%$ of body width. Epidermis ciliated just over creeping sole. Dorsal epidermis of anterior end crossed by scarce secretory cells containing erythrophil granules; ventral one crossed by abundant rhabditogen cells. In pre-pharyngeal traverse sections (Fig. 2), dorsal and marginal epithelium crossed by two types of abundant secretory cells containing erythrophil granules and rhabdites, respectively, as well as less abundant cells containing a kind of dark pinkish erythrophil granules. Ventral epidermis pierced by secretory cells of two types, one with xanthophil granules, another with rhabdites. Glandular margin absent. Three typical geoplaninid cutaneous muscle layers present: one circular followed by a diagonal with deccusate fibers, and then a longitudinal layer with fibers arranged into bundles with 8-12 fibers each. Cutaneous musculature thickness relative to body height at the pre-pharyngeal region (CMI), 10.9\% (see Froenlich 1955). In anterior body end, fibers of cutaneous muscle layers equally arranged but less apparent. Three parenchymal muscle layers: a dorsal layer of deccusate diagonal fibers, a supraintestinal layer of traverse fibers, and a subintestinal layer with traverse fibers, some of which penetrate the nervous tissue of the ventral nerve plate. Mouth in the posterior third of the pharyngeal pouch (Fig. 3). Pharyngeal pouch lined with a squamous, non-ciliated epithelium, underlain by a one-fiber thick layer of longitudinal muscles. Short esophagus. Pharynx cylindrical, with outer epithelium flat, ciliated with infra-nucleated cells, underlain by a layer of circular muscle fibers, followed by a layer of longitudinal fibers, both one-fiber thick. Inner pharyngeal epithelium flat, ciliated, infra-nucleated, underlain by a one-fiber thick layer of longitudinal fibers, followed by a layer (46 $\mu \mathrm{m}$ thick) of circular fibers, and a third layer of longitudinal fibers $(5 \mu \mathrm{m})$. Secretory cells of three types, containing cyanophil, erythrophil, and xanthophil granules, respectively, pierce the distal portion of the pharynx. Testes round, $300 \mu \mathrm{m}$ in diameter, located between supraintestinal parenchymal muscle layer and intestine (Fig. 2); extending from $5 \mathrm{~mm}$ behind anterior tip of the body up to $10.5 \mathrm{~mm}$ behind. Sperm ducts run dorsally to ovovitelline ducts. Distal portion of sperm ducts dilated, full of sperm, bent forward and medially to open laterally into the proximal region of the prostatic vesicle (Figs 4 and 6). Prostatic vesicle unforked, very close to the pharyngeal pouch, running posteriorly, proximally upwards, distally downwards; lining epithelium columnar, ciliated, and with ir- 

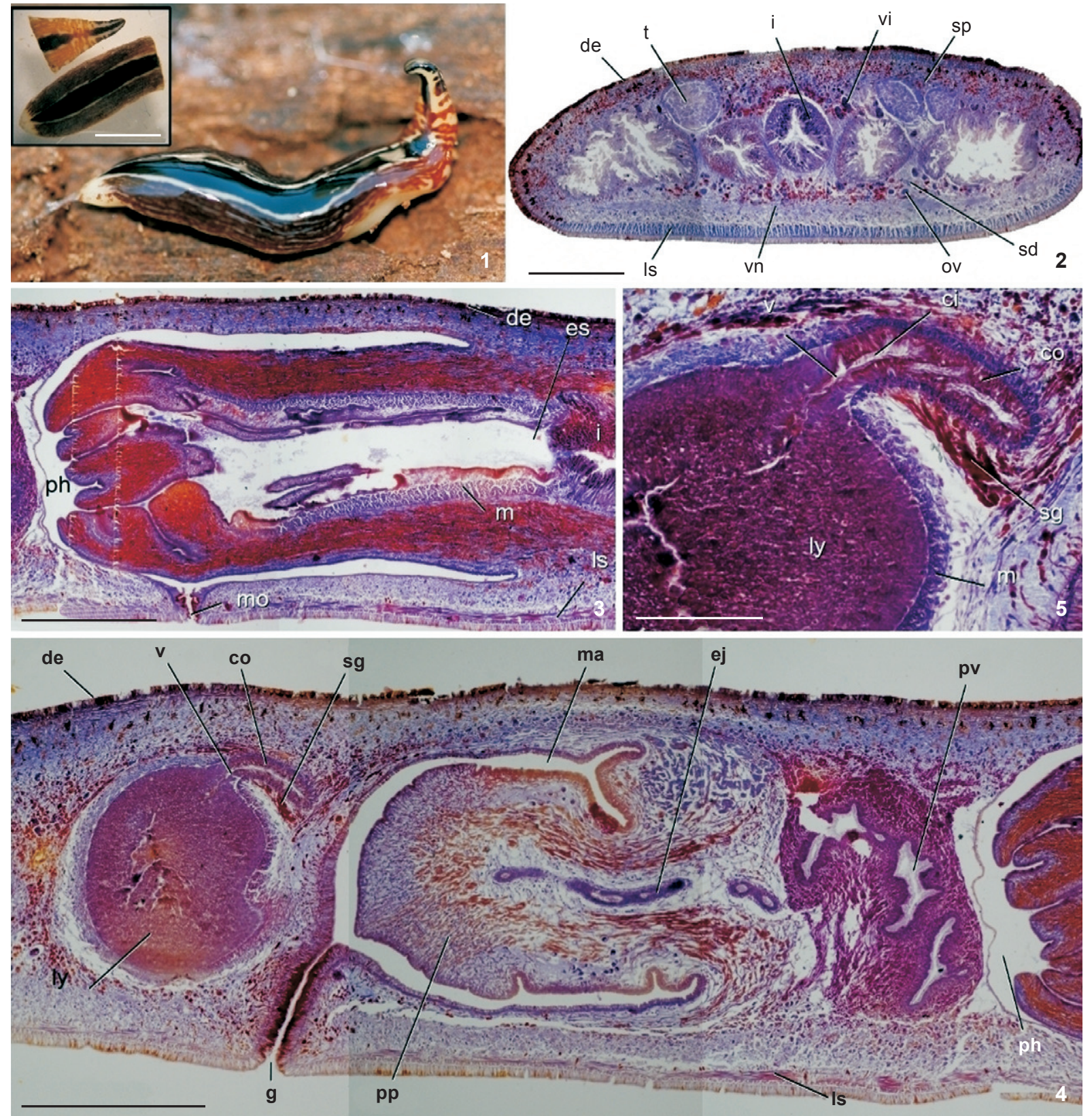

Figures 1-5. Geoplana piriana sp. nov., holotype. (1) General aspect of the live specimen, approximately $20 \mathrm{~mm}$ in length. Inset: fixed specimen after cutting off an intermediate piece of two millimeters. (2) Micrograph of a traverse section of pre-pharyngeal region. (3) Micrograph of a sagittal section of the pharynx. (4) Micrograph of a sagittal section of the copulatory apparatus. (5) Micrograph of a sagittal section showing the common glandular duct and the female atrium. Scale bars: $1=5.0 \mathrm{~mm}, 2-4=0.5 \mathrm{~mm}, 5=150 \mu \mathrm{m}$.

regular height, pierced by two types of secretory cells containing dark-pinkish erythrophil granules, and cyanophil granules, respectively; additionally, short proximal portion of vesicle pierced by secretory cells with xanthophil granules. Prostatic vesicle surrounded by layer (13-44 $\mu \mathrm{m}$ thick) of circular muscles.
Ejaculatory duct crosses the middle of the penis papilla. Penis papilla cylindrical, occupying entire male atrium; lined with a non-ciliated epithelium; lateral wall of penis papilla pierced by secretory cells containing fine, weakly cyanophil granules; tip of penis papilla pierced by secretory cells containing erythrophil 


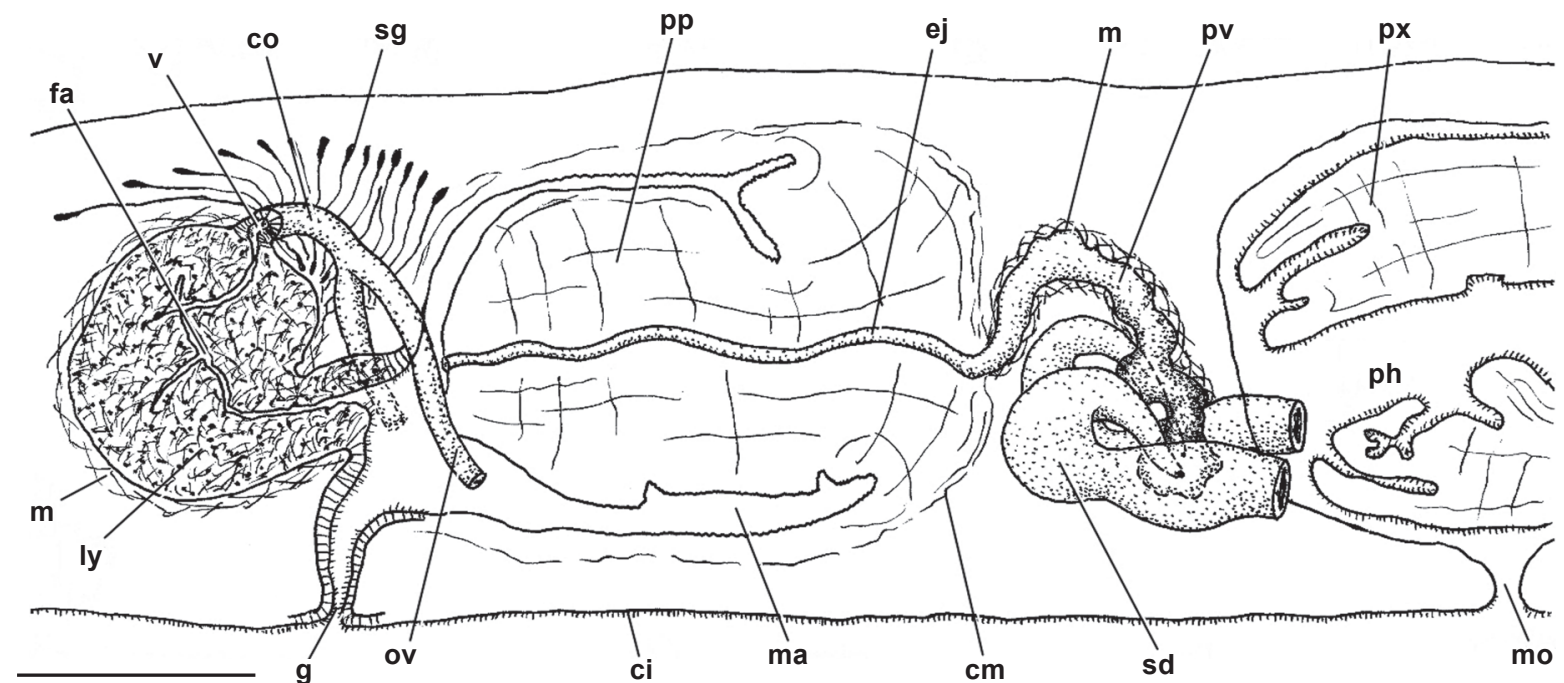

Figure 6. Geoplana piriana sp. nov., holotype. Diagrammatic reconstruction of copulatory apparatus from sagittal sections. Scale bar = $0.5 \mathrm{~mm}$.

granules; cell bodies of cyanophil secretory cells inside penis bulb; those of the erythrophil ones outside the penis bulb. Additionally, epithelium of the dorsal insertion of the papilla crossed by bundles of numerous cell necks containing cyanophil granules; cell bodies of these cells were not observed. Under epithelium of penis papilla, layer ( $5 \mu \mathrm{m}$ thick) of circular muscles followed by layer $(6 \mu \mathrm{m})$ of longitudinal muscles. Male atrium ample, with non-folded walls, lined with cuboidal, nonciliated epithelium with apical surface irregular; pierced by secretory cells containing amorphous xanthophil secretion; epithelium surrounded by a layer of circular muscles followed by a layer of longitudinal muscles, each layer $5 \mu \mathrm{m}$ thick. Ovaries round, $240 \mu \mathrm{m}$ in diameter, located $5 \mathrm{~mm}$ behind the anterior end, above ventral nerve plate. Vitellaria distributed around intestine and between main intestinal branches. Ovovitelline ducts emerge dorso-laterally from ovaries. Very distal ascending portion of ovovitelline ducts pierced by shell glands. Ovovitelline duct join each other dorsally to gonopore (Figs 4 and 5); ovovitelline duct underlain by an 8 - $\mu$ m thick layer of circular muscles. Common glandular ovovitelline duct directed dorsally towards body end (Fig. 6); underlain by an 8$\mu \mathrm{m}$ thick layer of circular muscle fibers followed by some longitudinal fibers. Short vagina projecting forwards from mid-dorsal region of female atrium, lined with a columnar, apically erythrophil, ciliated epithelium. Posterior region of female atrium rounded, anterior strongly narrowed; because the narrowed region is located in a lower position than the rounded one, the whole female atrium shows an aspect of being downwards inclined. Female atrium almost totally occupied by a non-ciliated epithelium with multilayered aspect, pierced by secretory cells containing erythrophil granules, underlain by a $30-\mu \mathrm{m}$-thick layer of muscle fibers variously ori- ented. Female atrium as long as a half of male atrium. Gonopore canal lined with a columnar ciliated epithelium, strongly erythrophil apically, pierced by two types of secretory cells, with amorphous xanthophil secretion and erythrophil granules, respectively. Epithelium of gonopore canal underlain by a layer $(3 \mu \mathrm{m})$ of circular muscle fibers, followed by layer of longitudinal fibers $(5 \mu \mathrm{m})$. Around gonopore canal, male and female atrial epithelia ciliated (Fig. 6).

Etymology. The specific epithet is a word of the TupiGuarani (a native people of Brazil) meaning longitudinally striped, a reference to the longitudinal arrangement of the brownish small striae of the lateral bands.

Remarks. Among the species of Geoplana having a female atrium lined with an epithelium with multilayered aspect, only six species - G. goettei Schirch, 1929 (Brazil), G. incognita Riester, 1938 (Brazil), G. phocaica Marcus, 1951 (Brazil), G. preta Riester, 1938 (Brazil), G. saima du Bois-Reymond Marcus, 1951 (Peru), and G. suva Froehlich, 1959 (Brazil) - resemble G. piriana Almeida \& Carbayo, sp. nov. in having an extrabulbar, nonbifurcated prostatic vesicle, and a female atrium anteriorly narrowed. Besides the very different color pattern of the dorsum, these six species also deviate from G. piriana Almeida \& Carbayo, sp. nov. in the details of the internal morphology. In G. goettei and $G$. suva the prostatic vesicle is divided into an anterior portion separated by a constriction from a second, distal one. In $G$. preta there is an annular fold in the posterior region of the male atrium separating it from the female atrium. In $G$. phocaica the penis papilla is only two-thirds of the male atrium length; the male atrium is richly folded, and the genital female canal opens into the posterior region of the female atrium. In G. incognita, from the same locality than G. piriana Almeida \& Carbayo, sp. nov., the prostatic vesicle is much shorter, and 
the penis papilla is cone-shaped. G. saima shares with the new species an additional uncommon feature, i.e., the common glandular ovovitelline duct opening into the anterior region of the female atrium region, thus resembling that of G. saima. Nonetheless, G. saima differs from G. piriana Almeida \& Carbayo in that in the Peruvian species the penis papilla is downwards inclined and the multilayered-like lining epithelium of the female atrium extends anteriorly up to the gonopore.

Regarding Pseudogeoplana Ogren \& Kawakatsu, 1990 (Geoplaninae) a genus for species from which only their external aspect is known, there are three species, P. bonita (Schirch, 1929), P. lumbricoides (Schirch, 1929), and P. tricolor (Riester, 1938), resembling G. piriana Almeida \& Carbayo, sp. nov. in showing longitudinal dorsal bands of brown-reddish and blackish pigment, respectively. The three species also occur in the type locality of G. piriana Almeida \& Carbayo, sp. nov. Nevertheless, $P$. bonita, a species having a similar body size, is different from G. piriana Almeida \& Carbayo, sp. nov. in having two pairs of blackish green stripes separated by a pair of orangish lateral stripes; in P. lumbricoides, $30 \mathrm{~mm}$ in body length, the dorsum is earthworm-reddish, excepting a thin whitish midline and the bluish-black margins. In P. tricolor, the body is also lanceoate, but it is smaller (only $9.5 \mathrm{~mm}$ in length)and the mid-line is yellowish, demarcated by lateral black stripes, and the margins are reddish.

\section{Geoplana tingauna Kishimoto \& Carbayo, sp. nov.}

Figs 7-17

Type material. Holotype: MZUSP PL 1150 (field number, F3258): Parque Estadual da Serra do Tabuleiro, Paulo Lopes,

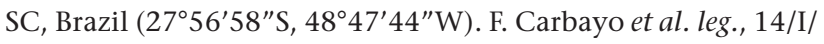
2009. Anterior region: traverse sections on 12 slides; pharynx plus copulatory apparatus: sagittal sections on 11 slides; posterior region in 100\% ethanol. Paratypes: MZUSP PL 1151 (field number, F3353): Parque Estadual da Serra do Tabuleiro, Paulo Lopes, SC, Brazil (2751'54.4"S, 48 55'09.8”W). F. Carbayo et al. leg., 18/I/2009. Anterior region in 80\% ethanol; Pharynx: horizontal sections on 7 slides; copulatory apparatus: sagittal sections on 7 slides; anterior and posterior ends in $80-100 \%$ ethanol. MZUSP PL 1152 (field number, F3354): Ibid. Anterior end: traverse sections on three slides; anterior region 2: sagittal sections on eight slides; pharynx plus copulatory apparatus: sagittal sections on six slides; posterior tip in 100\% ethanol.

Type-locality. Parque Estadual da Serra do Tabuleiro, Paulo Lopes, SC, Brazil, covered with dense ombrphilous forest.

Diagnosis. Geoplana species with $15-21 \mathrm{~mm}$ in length. Dorsum with 3-5 wide traverse dark bands on a whitish background. Paired branches of the prostatic vesicle open into the very distal portion of the tubular, unpaired one; penis papilla horizontal, conical-to-cylindrical; lining of female atrium with multilayered aspect.
Description. Live holotype $19 \mathrm{~mm}$ long, $1.8 \mathrm{~mm}$ wide (Tab. I). Body slender, subcylindric in cross-section; anterior end rounded, posterior pointed. Dorsal and ventral ground color whitish. On the anteriormost $3 \mathrm{~mm}$ of the dorsum, a mid-sagittal black band and a pair of marginal thin black stripes; posteriorly, three wide traverse brown, slightly ferruginous bands, the posterior ones being wider. Anterior and posterior borders of each traverse band black (Fig. 7). Scarce grayish-to-black spots on the traverse bands and between the posteriormost bands. At the posterior end, the greater number of black spots results in a kind of fourth traverse band. All bands extend onto the body margins and, incompletely onto the ventral side as spots (Fig. 7, inset). In paratypes the traverse bands are five in number and grayish black in color, extending incompletely onto the margin of the ventral sides (Fig. 8). After fixation, holotype $13 \mathrm{~mm}$ long and $2.5 \mathrm{~mm}$ wide. Mouth at $6.5 \mathrm{~mm}$ from behind the anterior end, gonopore at $8.5 \mathrm{~mm}$. Dorsum color lost the brightness after fixation. Eyes formed by one pigmented cup, $25 \mu \mathrm{m}$ in diameter, marginally arranged into an irregular row from anteriormost tip up to the posterior end; no clear halos around eyes. Sensory pits as simple invaginations $12 \mu \mathrm{m}$ deep, distributed ventro-laterally in a uniserial row from the very anterior tip to $1.5 \mathrm{~mm}$ behind. Creeping sole as wide as $81 \%$ of body width. Epidermis ciliated only in the creeping sole. Epidermis of anterior end pierced by scarce rhabditogen cells, only dorsally; other types of secretions could not be observed in the ill-stained sections. In pre-pharyngeal traverse sections, epithelium at the dorsal and marginal regions pierced by two types of very abundant secretory cells containing fine erythrophil granules and rhabdites, respectively; ventral epidermis pierced by cells of three types, with rhabdites, xanthophil granules, and cyanophil granules, respectively, the two former more abundant laterally. Three typical geoplaninid cutaneous muscle layers present: one circular followed by a diagonal with deccusate fibers, and then a third layer of longitudinal fibers arranged into bundles. Cutaneous musculature thickness relative to body height at the pre-pharyngeal region (CMI), 10.2-12\%. In anterior end of the body, muscle fibers of the layers simply become less apparent.

Table I. Body measurements of live and fixed specimens of Geoplana tingauna sp. nov.

\begin{tabular}{lrrc}
\hline \multicolumn{1}{c}{ Measurements } & Holotype & $\begin{array}{c}\text { MZUSP } \\
\text { PL 1151 }\end{array}$ & $\begin{array}{c}\text { MZUSP } \\
\text { PL 1152 }\end{array}$ \\
\hline Length alive & 19.0 & 15.5 & 21.0 \\
Width alive & 1.8 & 2.0 & 2.0 \\
L (length) & 13.0 & 14.5 & 16.0 \\
Width & 2.5 & 2.0 & 3.0 \\
M (mouth - anterior tip) & 6.5 & 6.5 & 9.5 \\
Relative M: L (\%) & 50.0 & 44.8 & 59.4 \\
G (gonopore - anterior tip) & 8.5 & 9.2 & 12.0 \\
Relative G: L (\%) & 65.4 & 63.4 & 75.0 \\
\hline
\end{tabular}



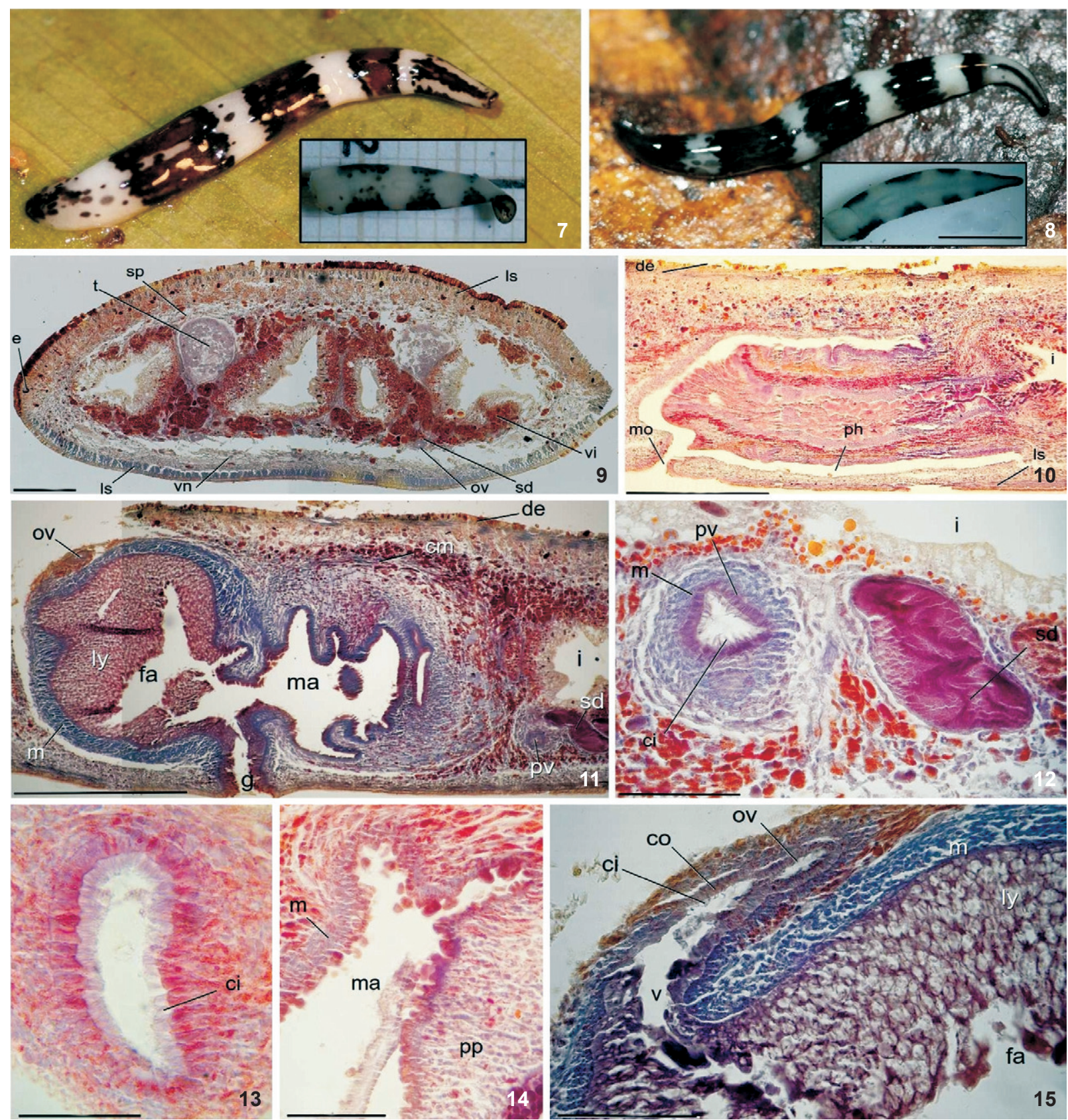

Figures 7-15. Geoplana tingauna sp. nov. (7) General aspect of the live holotype, approximately 19 mm in length. Inset: photograph of the fixed specimen on a millimetered paper after cutting off a piece end of $0.2 \mathrm{~cm}$. (8) General aspect of the live paratype MZUSP PL 1152, approximately $21 \mathrm{~mm}$ in length. Inset: fixed specimen after cutting off a piece of two millimeters. (9) Micrograph of a traverse section of pre-pharyngeal region of the holotype. (10) Micrograph of a sagittal section of the pharynx of the holotype. (11) Micrograph of a dorso-ventral oblique section (nearly sagittal) section of the copulatory apparatus of the holotype. (12) Micrograph of a sagittal section showing a sperm duct, full of sperm, and one of the paired branches of the prostatic vesicle of the paratype MZ PL 1151. (13) Micrograph of a sagittal section showing a branch of the prostatic vesicle of the holotype. The reddish specks are erythrophil granules. (14) Micrograph of a sagittal section showing the dorsal wall of the male atrium and of the penis papilla of the holotype. (15) Micrograph of a sagittal section showing the common glandular ovovitelline duct and female atrium of the holotype. Scale bars: $8=5 \mathrm{~mm}$, $10,11=0.5 \mathrm{~mm}, 9=250 \mu \mathrm{m}, 12,15=100 \mu \mathrm{m}, 13=25 \mu \mathrm{m}, 14=50 \mu \mathrm{m}$. 

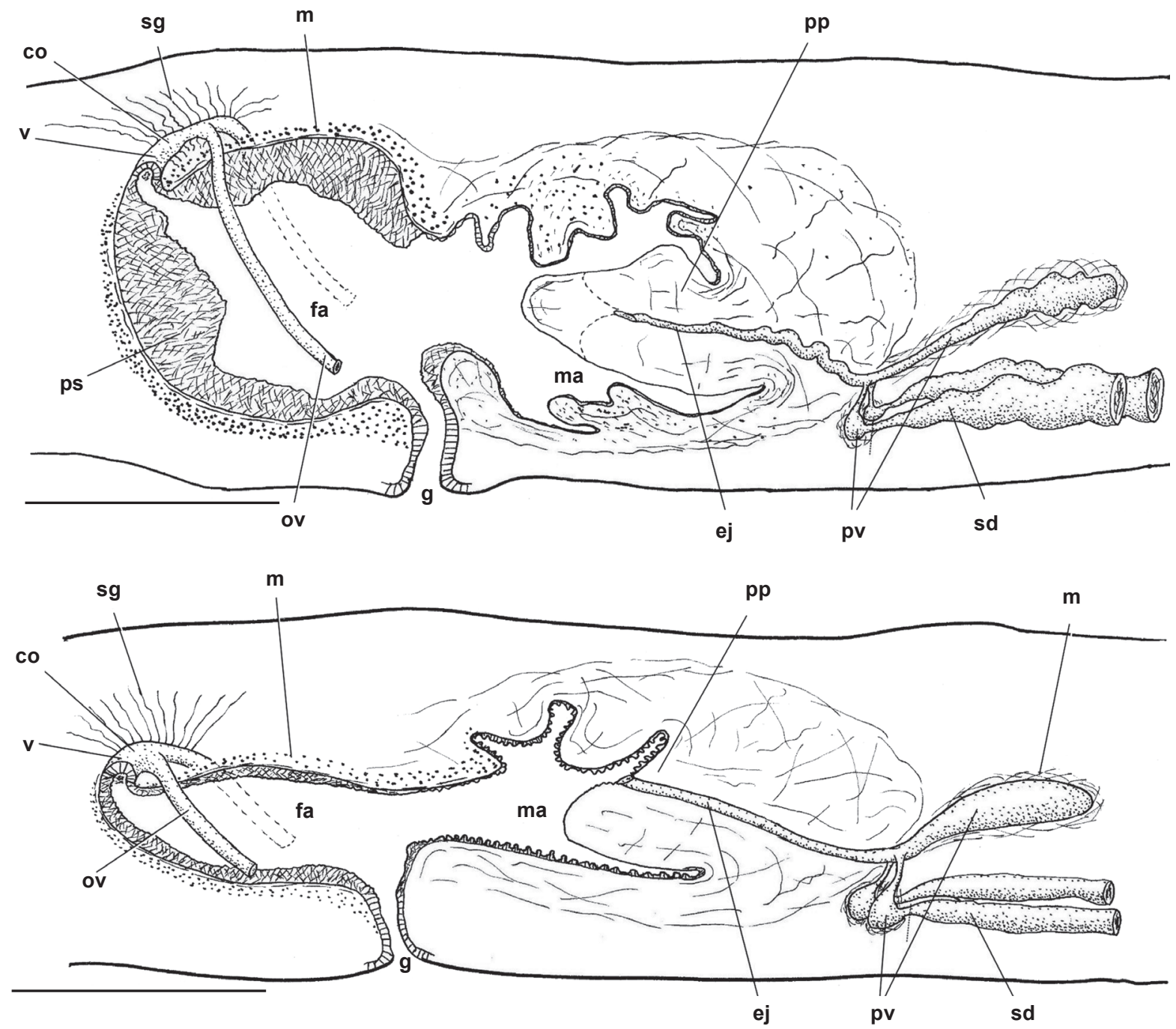

Figures 16-17. Geoplana tingauna sp. nov. Diagrammatic reconstruction of copulatory apparatus from sagittal sections of the (16) holotype and (17) the paratype MZ PL 1151. Scale bars: $0.5 \mathrm{~mm}$.

Three parenchymal muscle layers: a dorsal layer of deccusate diagonal fibers, a weak supraintestinal layer of traverse fibers, and a subintestinal layer with traverse fibers (Fig. 9).

Mouth at end of pharyngeal pouch (Fig. 10). Lining epithelium of pharyngeal pouch flat, non-ciliated, underlain by one-fiber thick layer of longitudinal muscle fibers. Pharynx cylindrical, with dorsal insertion slightly posterior to the ventral. Outer pharyngeal epithelium flat, ciliated, underlain by a 30 - $\mu$ m-thick layer of longitudinal muscle fibers, followed by one layer (20 $\mathrm{mm}$ thick) of circular fibers. Inner pharyngeal epithelium flat, ciliated, followed by a layer ( $20 \mu \mathrm{m}$ thick) of circular fibers followed by one-fiber thick layer of longitudinal muscle fibers. Secretory cells of three types, containing cyano- phil, erythrophil, and xanthophil granules, respectively, pierce the distal portion of the pharynx. Testes pre-pharyngeal, located between the supraintestinal parenchymal muscle layer and intestine, extending from $2.5 \mathrm{~mm}$ behind the anterior end up to $0.4 \mathrm{~mm}$ behind dorsal insertion of the pharynx (holotype). Sperm ducts - distally full of sperm in the three specimens -, horizontal, communicated with the two vertical, proximally dilated branches of the prostatic vesicle (Figs 11-12 and 16-17). Branches of prostatic vesicle open laterally into the distal region of the approximately horizontal, long unpaired portion of the prostatic vesicle (Figs 16-17). Paired prostatic vesicle lined with a cuboidal-to-columnar, ciliated epithelium, pierced by secretory cells containing fine erythrophil granules, much more abundant in the paratypes than in the holotype 
(Figs 12 and 13); paired branches surrounded by a dense layer $(20 \mu \mathrm{m})$ of circular muscle fibers. Unpaired portion of prostatic vesicle lined with a columnar, ciliated epithelium crossed by numerous secretory cells containing coarse erythrophil granules; surrounded by a layer of interwoven muscle fibers. Unpaired portion of the vesicle continued, inside the penis bulb, as an ejaculatory duct crossing the central region of the penis papilla. Penis papilla approximately horizontal, variable in shape, either irregularly conical (holotype, Fig. 16) or with no defined shape (Fig. 17), occupying about the anterior half of the male atrium. Penis papilla lined with a non-ciliated epithelium, with apical surface either smooth (holotype) or irregular (paratype MZUSP PL 1151, Fig. 14), underlain by a layer of circular muscle fibers. Distally, penis papilla pierced by secretory cells containing erythrophil granulous secretion. Male atrium ample, either with a ventral (holotype) or a dorsal distal fold (paratypes) partially separating the male from the female atrium. Male atrium lined with a cuboidal-to-columnar epithelium, non-ciliated, the apical surface of which smooth (holotype) or strongly irregular (paratypes). Two distal thirds of male atrium crossed by numerous cells containing erythrophil granular secretions, the necks of which are gathered into bundles. Male atrium lined with a layer (10 $\mu \mathrm{m}$ thick) of circular muscle fibers followed by one $(10 \mu \mathrm{m})$ of longitudinal fibers. Ovaries round, placed at the same traverse level as the anteriormost testes. Vitellaria around intestine and between main intestinal branches. Ovovitelline ducts emerge from the dorso-external aspect of ovaries; sperm stored in the anteriormost portion of ovovitelline ducts of holotype and paratype MZUSP PL 1152 (not analyzed in the the paratype MZUSP PL 1151). Ovovitelline ducts rise laterally to female atrium, then unite to the common glandular ovovitelline duct dorsally to the atrium. In holotype and paratype MZUSP PL 1151 distal portion of ovovitelline ducts receive shell glands (Figs 11 and 15-17); in paratype MZUSP PL 1152 shell glands absent in ovovitelline ducts. Common glandular ovovitelline duct directed downwards, continuous with the vagina, a forward directed diverticle of the dorso-posterior region of female atrium. Female atrium medianly dilated, having either a rounded (holotype) or an elongated shape (paratypes). Female atrium as long as the male one, lined with a non-ciliated epithelium, with a multilayered aspect, penetrated by cells containing erythrophil granules; epithelium of female atrium of holotype higher than in that of paratypes; surrounded by a thin layer of longitudinal muscle fibers followed by a thick layer of circular ones $(60 \mu \mathrm{m})$. Male muscle coat more conspicuous than female.

Etymology. The specific epithet is a composition from the Tupi-Guarani (native people of Brazil) words tinga, meaning white, and una, meaning black, dark, a reference to the color of the dorsum.

Biological note. The worms move slowly after exposure to daylight. The holotype was found at rest ca. at 17 hours; the couple of paratypes, found paired for breeding at midday, were fixed eight hours thereafter.

Remarks. The unique color pattern of the dorsum as well as the very peculiar shape of the prostatic vesicle, are features strongly supporting the co-specificity of the three specimens, and also provide differentiation of G. tingauna Kishimoto \& Carbayo, sp. nov. from any other Geoplanaspecies. Moreover, there are no Geoplaninae species either with traverse pigment bands on the dorsum along the entire body, nor with a prostatic vesicle formed by paired branches opening at the distal end of an unpaired portion (Pseudogeoplana species not available for comparison of the latter feature) with which G. tingauna Kishimoto \& Carbayo, sp. nov. could be misidentified.

\section{ACKNOWLEDGMENTS}

We thank the Instituto Chico Mendes de Conservação da Biodiversidade and FATMA (Fundação de Amparo e Tecnologia do Meio Ambiente de Santa Catarina) for licensing the fieldwork; Nivaldo Gularte (Paulo Lopes, SC) for the enthusiastic guidance and motorcycle rides up to the hills; Juan R.E. García (Paulo Lopes, SC) for his kind and generous hospitality; Júlio Pedroni for the picture of the living specimen of $G$. piriana; Ana C.M. Vasconcelos (EACH, USP) for helping with histological processing; Leonardo Zerbone (EACH, USP) for helping RGK with histological study; two anonymous reviewers for their valuable comments and suggestions. Academic EnglishSolutions.com revised the English. ALA was funded by Pró-Reitoria de Graduação (USP), RGK by PIBIC/CNPq; FC has financial support from Fundação de Amparo à Pesquisa do Estado de São Paulo (FAPESP).

\section{LITERATURE CITED}

Carbayo, F.; A.M. Leal-Zanchet \& E. Vieira. 2002. Terrestrial flatworm (Platyhelminthes: Tricladida: Terricola) diversity vs. man-induced disturbance in a subtropical rainforest from Southern Brazil. Biodiversity and Conservation 11: 10911104.

Carbayo, F. \& E.M. Froehlich. 2008. Estado do conhecimento dos macroturbelários (Platyhelminthes) do Brasil. Biota Neotropica 8 (4): 177-197. doi: S1676-06032008000400018

Fick, I. A.; A.M. Leal-Zanchet \& E.M. Vieira. 2006. Community structure of land flatworms (Platyhelminthes, Terricola): comparisons between Araucaria and Atlantic forest in southern Brazil. Invertebrate Biology 125 (4): 306-313. doi: 10.1111/j.1744-7410.2006.00062.x

Froenlich, C.G. 1955. Sôbre morfologia e taxonomia das Geoplanidae. Boletins da Faculdade de Filosofia, Ciências e Letras da Universidade de São Paulo, São Paulo, Série Zoologia, 19: 195-279.

Ogren, R.E. \& M. Kawakatsu. 1990. Index to the species of the family Geoplanidae (Turbellaria, Tricladida, Terricola) Part 
I: Geoplaninae. Bulletin of the Fuji Women's College, Serie II, 28: 79-166.

Ogren, R.E.; M. Kawakatsu; \& E.M. Froehlich. 1997. Additions and corrections of the previous land planarian indices of the world (Turbellaria, Seriata, Tricladida, Terricola) Addendum IV. Geographic locus index: Bipaliidae, Rhynchodemidae (Rhynchodeminae, Microplaninae), Geoplanidae (Geoplaninae, Caenoplaninae, Pelmatoplaninae). Bulletin of the Fuji Women's College, Serie I, 35: 63-103.

RomeIs, B. 1989. Mikroskopische Technik. München, Urban und Schwarzenberg, 697p.

SLuYs R. 1999. Global diversity of land planarians (Platyhelminthes, Tricladida, Terricola): a new indicator-taxon in biodiversity and conservation studies. Biodiversity and Conservation 8: 1663-1681.

Tyler, S.; S. Schilling; M. Hooge; \& L.F. Bush. 2006-2011. Turbellarian taxonomic database. Version 1.7. Available online at: http://turbellaria.umaine.edu [Accessed: 27/I/2012].

WINSOR, L.; P.M. Johns \& G.W. Yeates. 1998. Introduction, and ecological and systematic background, to the Terricola (Tricladida). Pedobiologia 42: 389-404.

Submitted: 13.III.2012; Accepted: 09.V.2012.

Editorial responsibility: Walter A.P. Boeger

ZOOLOGIA 29 (5): 430-438, October, 2012 